\title{
PERANCANGAN DAN IMPLEMENTASI APLIKASI PEMBELAJARAN INTERAKTIF ROBOTIC INVENTION SYSTEM PLATFORM MINDSTORM NXT MENGGUNAKAN METODE INKUIRI BERBASIS MACROMEDIA FLASH PLAYER (STUDI KASUS : UNIVERSITAS DHYANA PURA)
}

\author{
I Made Kusuma Wijaya ${ }^{1)}$ Putu Wida Gunawan') ${ }^{2}$.G.N Anom Cahyadi Putra ${ }^{3)}$ \\ Program Studi Teknik Informatika ${ }^{1)}$ ) 3) \\ Fakultas Ilmu Kesehatan, Sains Dan Teknologi, Universitas Dhyana Pura, Badung, Bali ${ }^{1 \text { (2) } 3)}$ \\ kusumawijaya21@gmail.com ${ }^{1)}$ putuwida@undhirabali.ac.id ${ }^{2)}$ anomcahyadi@undhirabali.ac.id ${ }^{3)}$
}

\begin{abstract}
Learning media is an intructional component that includes messages, people, and tools. Learning media can also be interpreted as a tool that serves to convey the message of learning. To convey learning messages, teachers typically use teaching aids such as books, pictures, maps, models, or other tools. In order to provide concrete experience, motivation to learn, and increase absorption. Learning media should be effective and in accordance with the needs of students. In the development of learning media follow the development of technology Dhyana Pura University is one of the campuses located in the city of Denpasar. Where the University Dhyna Pura has many courses, especially in informatics engineering courses. In the course of robotics NXT still a little tutorial and how to assemble NXT in NXT robotics courses. Then from that step done is to make an aplikasimedia NXT desktop-based robotics learning to simplify and reproduce the tutorial on the course of robotics NXT.
\end{abstract}

Keyword : Universitas Dhyana Pura, Media Pembelajaran, Robotika NXT

ABSTRAK

Media pembelajaran merupakan komponen intruksional yang meliputi pesan, orang, dan peralatan. Media pembelajaran juga dapat diartikan sebagai alat yang berfungsi untuk menyampaikan pesan pembelajaran. Untuk menyampaikan pesan pembelajaran, biasanya guru menggunakan alat bantu mengajar seperti buku, gambar, peta, model, atau alat-alat lain. Agar dapat memberikan pengalaman konkrit, motivasi belajar, dan meningkatkan daya serap. Media pembelajaran harus efektif dan sesuai dengan kebutuhan siswa. Dalam perkembangannya media pembelajaran mengikuti perkembangan teknologi. Universitas Dhyana Pura merupakan salah satu kampus yang terletak di kota Denpasar. Dimana Universitas Dhyana Pura memiliki banyak program studi khususnya di program studi teknik informatika. Pada mata kuliah robotika $N X T$ masih sedikit tutorial dan cara perakitan NXT pada mata kuliah robotika $N X T$. maka dari itu langkah yang dilakukan adalah membuat suatu aplikasimedia pembelajaran robotika $N X T$ berbasis desktop untuk mempermudah dan memperbanyak tutorial pada mata kuliah robotika $N X T$.

Kata kunci : Universitas Dhyana Pura, Media Pembelajaran, Robotika NXT 


\section{PENDAHULUAN}

Aplikasi media pembelajaran ini buat agar mahasiswa mudah untuk belajar secara visual dengan menampilkan materi tentang perakitan NXT selain itu karena adanya keter-batasan waktu pada mata kuliah kecerdasan buatan maka tentu mahasiswa tidak dapat membawa pulang set kotak lego NXT sehingga kurangnya pembelajaran tentang NXT maka dari itu aplikasi media pembelajaran ini bisa dipelajari dirumah. Permasalahan pada sistem pembelajaran sebelumnya dimana media pembelajaran dulunya hanya menggunakan buku panduaan sebagai media pembelajaran, seiring perkembangan zaman media pembelajaran kini berkembang dimana salah satunya dengan aplikasi macromedia flash dimana aplikasi tersebut membuat media pembelajaran jadi lebih menarik karena dilengkapi dengan pembuatan animasi, audio maupun video.

Adapun hubungan media pembelajaran dengan robot yang kini diterapkan di Indonesia adalah salah satunya pembelajaran robotika NXT yang bisa digunakan di dunia teknologi, seperti halnya pada kampus Universitas Dhyana Pura pembelajaran robotika NXT telah diterapkan pada mata kuliah kecerdasan buatan dan robotika. Dengan adanya materi kuliah kecerdasan buatan dan robotika tersebut nantinya media pembelajaran interaktif tersebut bisa diterapkan efektif pada kampus. Robot biasanya digunakan untuk tugas berat, bahaya, pekerjaan berulang dan kotor. Robot saat ini telah banyak dimanfaatkan oleh industri-industri di dunia.

Dalam upaya meningkatkan efisiensi dan efektifitas berbagai aktifitas kerja manusia. Salah satu teknologi robot yang terkenal saat ini adalah LEGO NXT dengan platform Mindstorm NXT. NXT merupakan penyempurnaan dari robot lego seri RIS (Robotic Invention System) yang telah sukses di pasaran. "Seri NXT merupakan seri robot yang lebih ramah dan relatif mudah untuk digunakan tanpa harus merekayasa sirkuit maupun memasang motor sendiri seperti generasi pendahulunya Pengenalan lego. NXT kepada anak usia dini sampai tingkat remaja sangat berpengaruh untuk membantu merangsang imajinasi dan kreatifitas. Perkembangan teknologi yang pesat akan sangat berguna jika dapat diaplikasikan pada sistem pengenalan lego NXT. Pada mata kuliah kecerdasan buatan dan robotika di kampus Universitas Dhyana Pura mahasiswa diajarakan untuk merakit sebuah robot lego NXT, mata kuliah kecerdasan buatan dan robotika Universitas Dhyana Pura masih konvesional untuk itu diperlukan media pembelajaran yang dapat diakses secara mudah seperti aplikasi yang menggunakan macromedia flash sehingga nanti mudah untuk diterapkan oleh para kalangan mahasiswa.

\section{TINJAUAN PUSTAKA}

\section{Metode Inkuiri}

Menurut Sanjaya (2012), metode pembelajaran Inkuiri adalah strategi pembelajaran inkuiri, yakni rangkaian kegiatan pembelajaran yang menekankan pada proses berpikir secara kritis dan analitis untuk mencari dan menemukan sendiri jawaban dari suatu masalah yang dipertanyakan. Proses berpikir itu sendiri biasanya dilakukan melalui tanya jawab antara guru dan siswa. Strategi pembelajaran ini sering juga dinamakan strategi heuristic, yang berasal dari bahasa Yunani, yaitu heuriskein yang berarti saya menemukan.

Strategi Pembelajaran Inkuiri (SPI) berangkat dari asumsi bahwa sejak manusia lahir ke dunia, manusia memiliki dorongan untuk menemukan sendiri pengetahuannya. Rasa ingin tahu tentang keadaan alam disekelilingnya merupakan kodrat manusia sejak ia lahir ke dunia. Sejak kecil manusia memiliki keinginan untuk mengenal segala sesuatu melalui indera pengecapan, pendengaran, penglihatan, dan indera-indera lainnya. Hingga dewasa keingintahuan manusia secara terus-menerus berkembang dengan menggunakan otak dan pikirannya. Pengetahuan yang dimiki manusia akan bermakna (meaningfull) manakala didasari oleh keingintahuan itu. Dalam rangka itulah strategi inkuiri dikembangkan (Sanjaya, 2012:197). Ada beberapa hal yang menjadi ciri utama metode pembelajaran inkuiri yang menurut 
Sanjaya (2012: 197) adalah strategi pembelajaran inkuiri yang meliputi:

Strategi inkuiri menekankan kepada aktivitas siswa secara maksimal untuk mencari dan menemukan, artinya stra-tegi inkuiri menempatkan siswa seba-gai subjek belajar. Dalam proses pem-belajaran, siswa tidak hanya berperan sebagai penerima pelajaran melalui penjelasan guru secara verbal, tetapi mereka berperan untuk menemukan sendiri inti dari materi pelajaran itu sendiri.

Seluruh aktivitas yang dilakukan siswa diarahkan untuk mencari dan menemu-kan jawaban sendiri dari sesuatu yang ditanyakan, sehingga diharapkan dapat menumbuhkan sikap percaya diri (self belief). Dengan demikian, strategi pembelajaran inkuiri menempatkan guru bukan sebagai sumber belajar, akan te-tapi sebagai fasilitator dan motivator belajar siswa.

Aktivitas pembelajaran biasanya dila-kukan melalui proses Tanya jawab an-tara guru dan siswa. Oleh sebab itu, ke-mampuan guru dalam menggunakan teknik bertanya merupakan syarat uta-ma dalam melakukan inkuiri.

Tujuan dari penggunaan strategi pembelajaran inkuiri adalah mengembang-kan kemampuan berfikir secara siste-matis, logis, dan kritis, atau men-gembangkan kemampuan intelektual sebagai bagian dari proses mental. Dengan demikian, dalam strategi pem-belajaran inkuiri siswa tak hanya dituntut agar menguasai materi pelajaran, akan tetapi bagaimana mereka dapat menggunakan potensi yang dimi-likinya. Manusia yang hanya mengua-sai pelajaran belum tentu dapat men-gembangkan kemampuan berpikir se-cara optimal, namun sebaliknya siswa akan dapat mengembangkan kemam-puan berpikirnya manakala ia bisa menguasai materi pelajaran.

\section{Lego Mindstorms NXT}

Seiring dengan perkembangan teknologi yang cukup pesat ini, robot bukan lagi pada suatu konsep yang sulit seperti yang kita tahu sebelumnya, namun robot merupakan bentuk alat bantu manusia yang dapat diaplikasikan pada kehidupan sehari-hari. Dengan kreatifitas generasi muda dan kalangan professional dalam mendesain dan membuat program pada robot, pemrograman terhadap device robotika dapat dilakukan dengan menggunakan high level language, atau menggunakan drag and drop Inovasi ini akan menjadi terobosan baru dalam hal pemrograman terhadap peralatan robotika, sehingga teman-teman pelajar akan dipermudah dalam penerapan segi elektriknya dan dapat lebih berkonsentrasi terhadap perintah-perintah logikanya. Selain dari kemudahan yang ditawarkan oleh Robot LEGO NXT Mindstorm.

LEGO Mindstorms NXT adalah pe-rangkat robot edukasional keluaran LEGO. Seri NXT ini resmi dirilis pada tahun 2006 sebagai penerus dari seri sebelumnya, yaitu RIS (Robotics Invention System) yang sukses di pasaran. Penggunaan Mindstorms NXT membantu mempermudah pembuatan robot. Hal ini dikarenakan Mindstorms NXT menghilangkan kebutuhan untuk menyolder sirkuit dan menghilangkankesulitan saat pemasangan motor. Robot yang dibuat menggunakan LEGO tidak dapat dianggap sebagai sebuah robot final, tapi dapat dianggap sebagai sebuah model. Perangkat robot LEGO tersedia dalam 2 versi, yaitu Retail dan Educational. Untuk membuat program yang berjalan di Mindstorms NXT, tersedia banyak pilihan. LEGO sendiri sudah menyediakan sebuah aplikasi yang dikenal dengan nama NXT-G (NXT Graphical Programming). Microsoft juga menyediakan aplikasi Microsoft Robotics Studio (Robotics Studio) yang dapat digunakan dengan berbagai jenis robot termasuk LEGO Robotics Studio. 


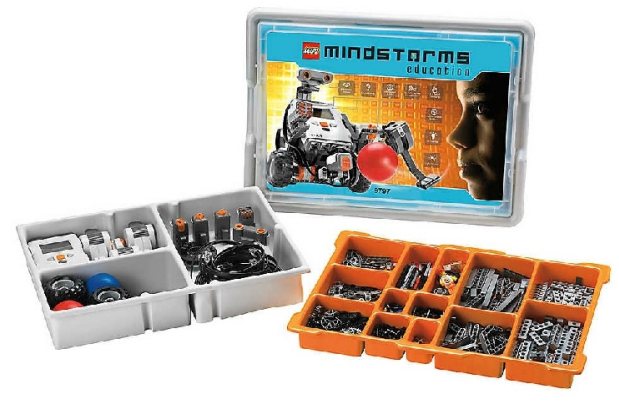

Gambar 1. LEGO Mindstorms NXT

\section{Sejarah Media Pembelajaran}

Media pembelajaran merupakan komponen intruksional yang meliputi pesan, orang, dan peralatan. Media pembelajaran juga dapat diartikan sebagai alat yang berfungsi untuk menyampaikan pesan pembelajaran. Untuk menyampaikan pesan pembelajaran, biasanya guru menggunakan alat bantu mengajar seperti buku, gambar, peta, model, atau alat-alat lain.

Agar dapat memberikan pengalaman konkrit, motivasi belajar, dan meningkatkan daya serap. Media pembelajaran harus efektif dan sesuai dengan kebutuhan siswa. Dalam perkembangannya media pembelajaran mengikuti perkembangan teknologi. Ada beberapa media yang mampu menyajikan materi pelajaran sejarah secara menarik dan mudah untuk dipahami, antara lain:

\section{Media Hasil Teknologi Cetak}

Teknologi cetak adalah cara untuk menghasilkan atau menyampaikan materi, seperti buku dan materi visual statis terutama melalui proses percetakan mekanis atau photografis. Kelompok media hasil teknologi cetak antara lain: teks, grafik, foto atau representasi fotografik. karakteristik media hasil cetak :

- Teks dibaca secara linear,

- Menampilkan komunikasi secara satu arah dan reseptif,

- Ditampilkan secara statis atau diam,

- Pengembangannya sangat tergantung kepada prinsip-prinsip pembahasan,

- Berorientasi atau berpusat pada siswa.

\section{Media Hasil Teknologi Audio-Visual}

Teknologi audi-visual cara menyampaikan materi dengan menggunakan mesinmesin mekanis dan elektronis untuk menyajikan pesan-pesan audio-visual penyajian pengajaran secara audio-visual jelas bercirikan pemakaian perangkat keras selama proses pembelajaran, seperti: mesin proyektor film, tape rekorder, proyektor visual yang lebar. Karakteristiknya:

- Bersifat linear,

- Menyajikan visual yang dinamis,

- Digunakan dengan cara yang telah ditentukan sebelumnya oleh perancang,

- Merupakan representasi fisik dari gagasan real atau abstrak,

- Dikembangkan menurut prinsip psikologis behafiorisme dan kognitif,

- Berorientasi pada guru.

\section{Media Hasil Teknologi Yang \\ Berdasarkan Komputer}

Teknologi berbasis komputer merupakan cara menghasilkan atau menyampaikan materi dengan menggunakan sumber-sumber yang berbasis.

\section{Micro-prosesor.}

Berbagai aplikasi teknologi berbasis komputer dalam pembelajaran umumnya dikenal sebagai computer assisted instruction. Aplikasi tersebut apabila dilihat dari cara penyajian dan tujuan yang ingin dicapai meliputi tutorial : penyajian materi secara bertahap, latihan untuk membantu siswa menguasai materi yang telah dipelajari sebelumnya, permainan dan simulasi (latihan untuk mengaplikasikan pengetahuan dan keterampilan yang baru dipelajari, dan basis data). Sumber yang dapat membantu siswa menambah informasi dan pengetahuan sesuai dengan keinginan masing-masing. Karakteristik media hasil teknologi yang berdasarkan komputer :

- Dapat digunakan secara acak, nonsekuensial atau secara linear.

- Dapat digunakan sesuai keinginan siswa atau perancang. 
- Gagasan disajikan dalam gaya abstrak dengan simbol dan grafik.

- Prinsip-prinsip ilmu kognitif untuk mengembangkan media ini.

- Berorientasi pada siswa dan melibatkan interaktifitas siswa yang tinggi.

\section{Media Hasil Gabungan Tenologi Cetak Dan Teknologi Computer}

Teknologi gabungan adalah cara untuk menghasilkan dan menyampaikan materi yang menggabungkan pemakaian beberapa bentuk media yang dikendalikan komputer. Komputer yang memiliki kemampuan yang hebat seperti jumlah Random Akses Memory yang besar, Hard Disk yang besar, dan Monitor yang beresolusi tinggi ditambah dengan pararel (alat-alat tambahan), seperti: video disk player, perangkat keras untuk bergabung dalam suatu jaringan dan sistem audio. Karakteristik Media hasil gabungan teknologi cetak dan teknologi komputer :

- Dapat digunkan secara acak, sekuensial atau secara linear,

- Dapat digunakan sesuai keinginan siswa, bukan saja dengan direncanakan dan diinginkan oleh perancangnya,

- Gagasan disajikan secara realistik se-suai dengan pengalaman siswa, me-nurut apa yang relefan dengan siswa dan dibawah pengendalian siswa,

- Prinsip ilmu kognitif dan konstruktifisme ditetapkan dalam pengembang-an dan penggunaan pelajaran,

- Pembelajaran ditata dan terpusat pada lingkup kognitif sehingga pengetahuan dikuasai jika pengetahuan itu digunakan,

- Bahan-bahan pelajaran melibatkan interaktif siswa,

- Bahan-bahan pelajaran memadukan ka-ta dan visual dari berbagai sumber.

Gerlach \& Ely (dalam Sihkabuden, 2005: 46) mengemukakan dalam penggunaannya, media tidak dapat langsung digunakan begitu saja oleh pengajar karena diperlukan suatu prosedur dalam proses pemilihannya. Oleh sebab itu, pemilihan dan penggunaan media harus benar-benar tepat agar tujuan yang diinginkan dapat tercapai dengan mudah. Pada akhirnya, pemanfaatan dan penggunaan media dapat menunjang efektifitas, efisiensi dan daya tarik dalam pembelajaran. Kearsley (dalam Sihkabuden, 1985 : 46) mengungkapkan prosedur dalam pemilihan suatu media dalam proses belajar mengajar sebagai berikut : Identifikasi ciriciri media yang diperlukan sesuai dengan kondisi. Identifikasi karakteristik pebelajar. Identifikasi karakteristik lingkungan belajar berkenaan dengan media yang akan digunakan. Identifikasi pertimbangan praktis yang memungkinkan media mana yang mudah digunakan dan dilaksanakan. Identifikasi faktor ekonomi. Mudhoffir (1999: 82) dalam bukunya Teknologi Instruksional, menyebutkan ada beberapa prinsip pemilihan media adalah sebagai berikut : Kesesuaian dengan tujuan pengajaran Tingkat kemampuan siswa Ketersediaan media Biaya Mutu teknik media. Sedangkan Brown, Lewin \& Harcleroad (dalam Sihkabuden, 1985 : 47) mempunyai pendapat dalam prinsip-prinsip pemilihan suatu media yaitu: Tidak ada media yang menggantikan kedudukan dan peranan guru seratus persen dalam kelas. Tidak ada satupun media yang paling untuk mencapai tujuan pembelajaran. Media harus sesuai dengan tujuan pembelajaran. Media harus mempertimbangkan kesesuaian antara penggunaan dan cara pembelajaran yang dipilih. Pemilihan media jangan hanya bergantung pada pemilihan dan penggunaan media tertentu saja. Pemakaian media harus dilandasi dengan pemanfaatan yang baik dan juga didukung oleh faktor lingkungan.

\section{METODELOGI PENELITIAN}

\section{Lokasi Penelitian}

Penelitian ini bertempat di Program

Studi Teknik Informatika Universitas Dhyana Pura yang berlokasi di Jl. Raya Padang Luwih, Tegaljaya,Dalung, Kuta Utara, Bali. Sejarah singkat Universitas Dhyana Pura Nama Dhyana Pura telah dipakai sejak berdirinya tahun 1987 sebagai Pusat Pendidikan dan Latihan Pariwisata Dhyana 
Pura yang selalu berusaha untuk mempertahankan kualitas pendidikan dan kualitas lulusannya.

\section{Kerangka Berpikir}

Pembelajaran kecerdasan buatan robotic NXT yang menggunakan set kotak lego NXT untuk perakitan NXT dimana perakitan tersebut dilakukan pada jam kuliah kecerdasan buatan. Sehingga kurangnya waktu belajar mahasiswa karena pembelajaran tersebut dilakukan pada jam kuliah saja. Karena set kotak lego NXT tersebut tidak bisa dibawa pulang, oleh karena itu diperlukan media pembelajaran robotic NXT yang dapat dipelajari tidak hanya pada jam kuliah saja namun bisa dipelajari di rumah. Maka dari itu akan buat aplikasi Pembelajaran Interaktif System Platform Mindstorms NXT Berbasis Macromedia Flash Player pada skripsi ini, akan dibuat dengan menggunakan perangkat lunak Macromedia Flash Player.

\section{Metode Pengumpulan Data \\ Studi Literatur}

Dalam tahap ini, dilakukan kegiatan dalam pengumpulan data-data pendukung dan literatur dimana untuk membangun aplikasi ini yang digunakan untuk media pembelajaran berbentuk aplikasi pembelajaran Interaktif Robotic Invention System platform Mindstorms NXT Berbasis Macromedia Flash Player. Pada tahap ini sumbersumber yang dapat diperoleh berupa buku, jurnal, internet dan lain-lain dimana informasi tersebut didapat dengan relevan dengan penelitian untuk meningkatkan proses pembuatan Aplikasi Pembelajaran Interaktif Robotic Invention System platform Mindstorms NXT Berbasis Macromedia Flash Player Menggunakan Metode Inkuiri (Studi Kasus : Universitas Dhyana Pura).

\section{Observasi}

Observasi pengumpulan data dilakukan meninjau langsung tempat penelitian dimana tempat tersebut letaknya di Unviersitas Dhyana Pura dan pengumpulan datanya berupa set kotak Robotic Invention System platform Mindstorms NXT.

\section{Metode Analisis dan Perancangan}

Disini penulis menggunakan metode pengembangan perangkat lunak yang dikenal dengan istilah SDLC (Software Development Life Cycle). Penulis menggunakan metode ini karena dengan menggunakan metedologi ini sangat memudahkan penulis menentukan sukses atau tidaknya proyek software yang dibuat.

\section{Flowchart}

Flowchart Login

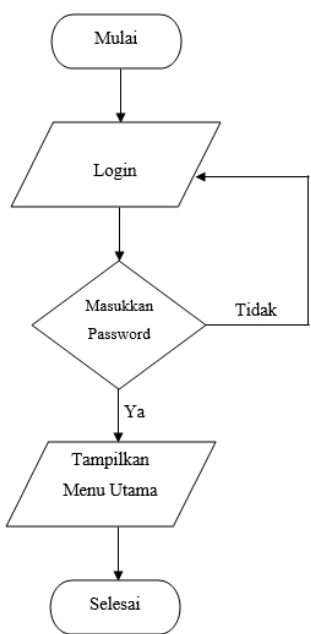

Gambar 2. Flowchart Login

Dimana proses memulai aplikasinya akan masuk ke menu, kemudian, nantinya akan disarankan untuk memilih menu yang diinginkan jika ya masuk kedalam media pembelajaran jika tidak maka akan kembali ke menu utama.

\section{Flowchart Sejarah NXT}

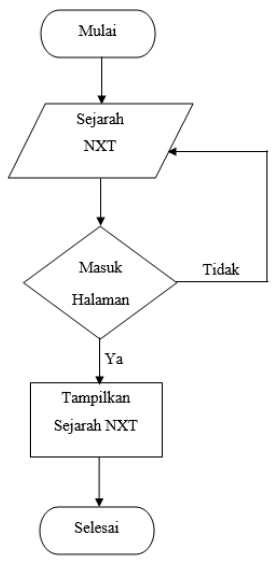

Gambar 3. Flowchart Sejarah NXT 
Pada gambar 3 diatas menjelaskan bagaimana aplikasi ini bekerja, dimulai dengan menjalankan aplikasi kemudian masuk ke tampilan menu utama dan masuk kehalaman kemudian nantinya akan langsung masuk untuk milihat sejarah dari NXT.

\section{Flowchart Perakitan NXT}

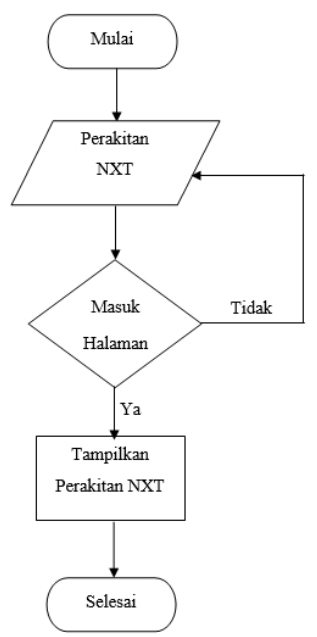

\section{Gambar 4. Flowchart Perakitan NXT}

Pada gambar 4 diatas menjelaskan bagaimana aplikasi ini bekerja, dimulai dengan menjalankan aplikasi kemudian masuk ke tampilan menu utama dan masuk ke halaman kemudian nantinya akan langsung masuk untuk milihat video dan juga disertai langkah-langkah pembuatan dalam bentuk teks.

\section{Flowchart Versi NXT}

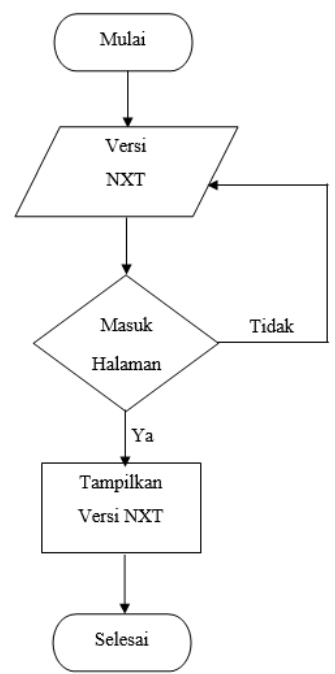

Gambar 5. Flowchart Versi NXT
Pada gambar 5 diatas menjelaskan bagaimana aplikasi ini bekerja, dimulai dengan menjalankan aplikasi kemudian masuk ke tampilan menu utama dan masuk ke halaman kemudian nantinya akan langsung masuk untuk milihat perkembangan versi NXT dari dahulu hingga sekarang.

\section{Flowchart Quiz}
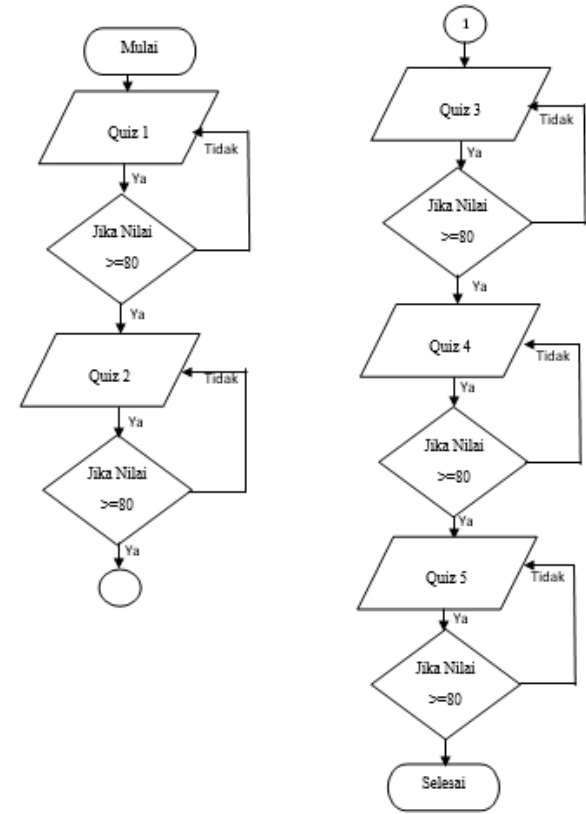

Gambar 6. Flowchart Quiz NXT

Pada gambar 6 diatas menjelaskan bagaimana aplikasi ini bekerja, dimulai dengan menjalankan aplikasi kemudian masuk ke tampilan menu utama dan masuk ke halaman kemudian nantinya akan langsung masuk untuk isikan nama dan mengerjakan quiz yang telah disediakan.

\section{DFD (Data Flow Diagram)}

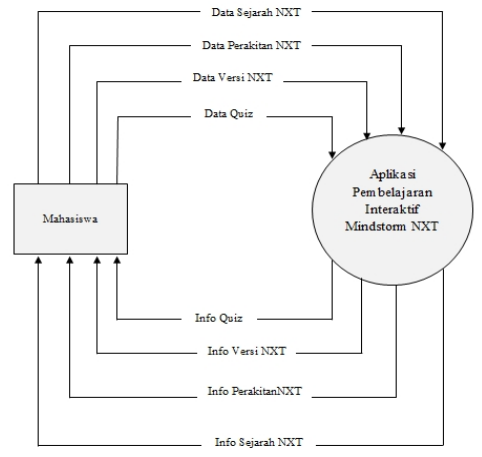

Gambar 7. Diagram Konteks 


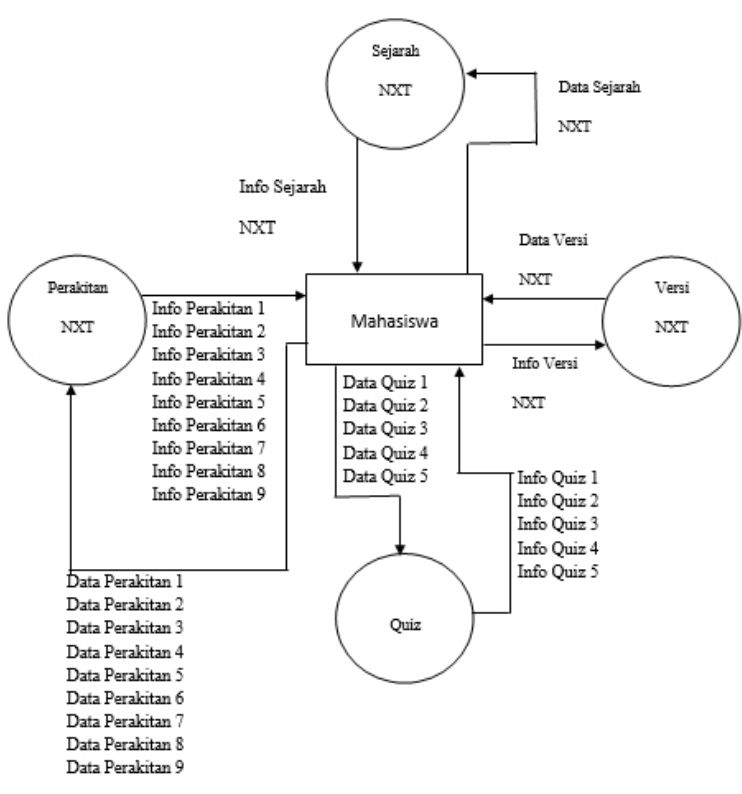

Gambar 8. DFD Level 0

\section{IMPLEMENTASI}

\section{Kebutuhan Sistem}

Setelah sistem aplikasi dianalisis dan didesain secara rinci, maka akan langsung menuju tahapan implementasi. Implementasi merupakan tahap meletakkan sistem sehingga siap untuk dioperasikan. Implementasi bertujuan untuk mengkonfirmasi modul-modul perancangan, sehinga pengguna dapat memberikan masukan kepada pembangun system aplikasi.

\section{Kebutuhan Perangkat Keras}

Perangkat keras yang digunakan untuk mengimplementasikan sistem adalah:

1. Laptop Acer $4732 \mathrm{z}$

2. Prosesor Intel Pentium (R) Dual-Core CPU $2.20 \mathrm{GHz}$

3. RAM 3 GB

4. Hardisk $100 \mathrm{~GB}$

5. Keyboard dan Mouse

\section{Kebutuhan Perangkat Lunak}

Perangkat lunak yang digunakan untuk mengimplementasikan system aplikasi adalah sebagai berikut :

1. Sistem Operasi Windows 7 Ultimate SP 1

2. Macromedia Flash Player Propesional 8

3. Adobe Photoshop CS3
4. Mobile Media Converter

5. Quick Time

\section{Tahapan Pembuatan Aplikasi}

Adapun tahapan awal sebelum proses pembuatan aplikasi yaitu dimulai dengan menginstall beberapa perangkat lunak di komputer, seperti Macromedia Flash Player 8, Adobe Photoshop, Mobile Media Converter.

\section{Antarmuka Loading}

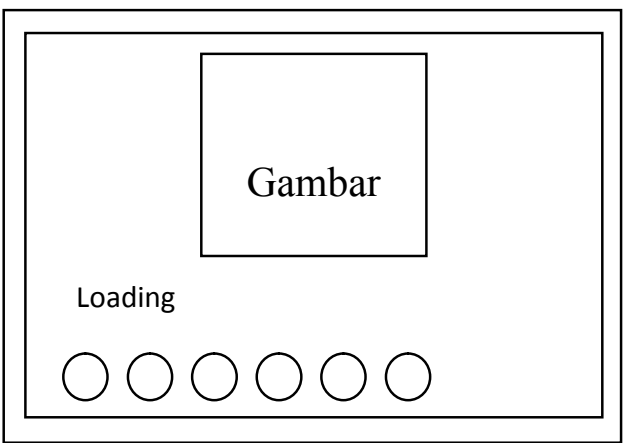

Gambar 9. Antarmuka Loading

Gambar 9 menunjukkan desain interface pada tampilan loading pada Aplikasi Pembelajaran Interaktif Robotic Invention System platform Mindstorm NXT Berbasis Macromedia Flash Player Menggunakan Metode Inkuiri (Studi Kasus : Teknik Informatika Universitas Dhyana Pura) dimana loading tersebut nantinya akan masuk ke menu utama.

\section{Antarmuka Memilih}

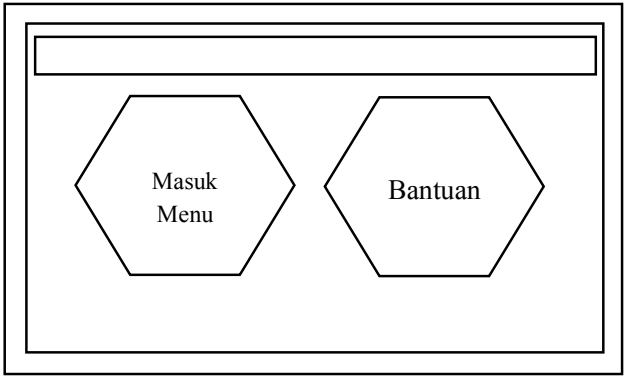

Gambar 10. Antarmuka Memilih

Gambar 10 menunjukkan desain interface pada tampilan memilih dimana pada pilihan masuk menu untuk masuk ke halaman utama dan pada tombol bantuan untuk panduan untuk penggunaan aplikasi pada Aplikasi 
Pembelajaran Interaktif Robotic Invention System platform Mindstorms NXT Berbasis Macromedia Flash Player Menggunakan Metode Inkuiri (Studi Kasus : Teknik Informatika Universitas Dhyana Pura) dimana loading tersebut nantinya akan masuk ke menu utama.

\section{Antarmuka Pilihan}

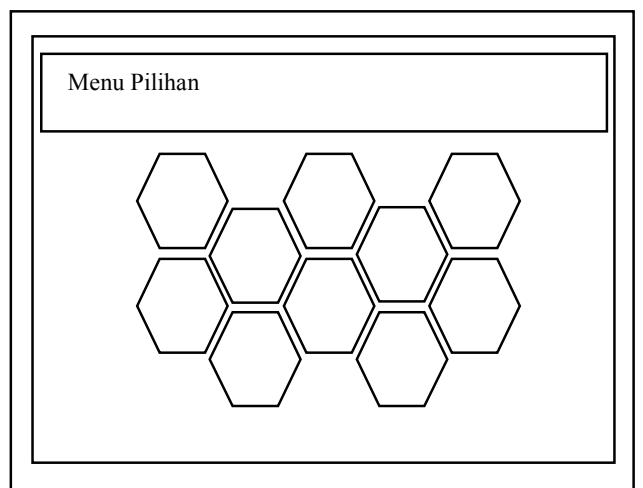

Gambar 11. Antarmuka Pilihan

Gambar 11 menunjukkan desain interface pada tampilan pilihan dimana pada menu pilihan untuk masuk ke perakitan NXT dimana pada menu ini akan disediakan tampilan un-tuk memulai programnya aplikasi pada Apli-kasi Pembelajaran Interaktif Robotic Invention System platform Mindstorms NXT Berbasis Macromedia Flash Player Meng-gunakan Metode Inkuiri (Studi Kasus : Tek-nik Informatika Universitas Dhyana Pura) dimana loading tersebut nantinya akan masuk ke menu utama.

\section{Antarmuka Menu}

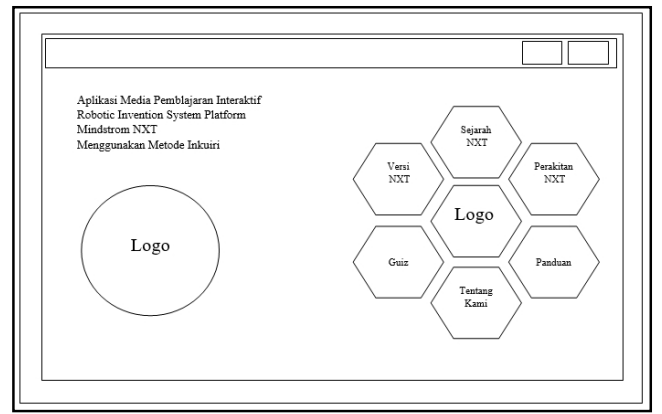

Gambar 12. Antarmuka Menu
Gambar 12 menunjukkan desain interface menu, dimana menu tersebut terdapat menu pengenalan dimana isi dari menu tersebut adalah sejarah NXT, kemudian menu perakitan NXT isinya tutorial perakitan robot NXT yang cukup sederhana, selanjutnya menu pada versi NXT adalah menu yang isinya versi dari robotika NXT, selanjutnya menu quiz yang isinya soal dari hasil materi robotika NXT, kemudian menu panduan berisikan cara penggunaan program NXT robotika, kemudian menu tentang kami menu tersebut isi dari versi dari aplikasi tersebut dan pembuat Aplikasi Pembelajaran Interaktif Robotic Invention System platform Mindstorms NXT Berbasis Macromedia Flash Player Meng-gunakan Metode Inkuiri (Studi Kasus : Tek-nik Informatika Universitas Dhyana Pura).

\section{Antarmuka Logout}

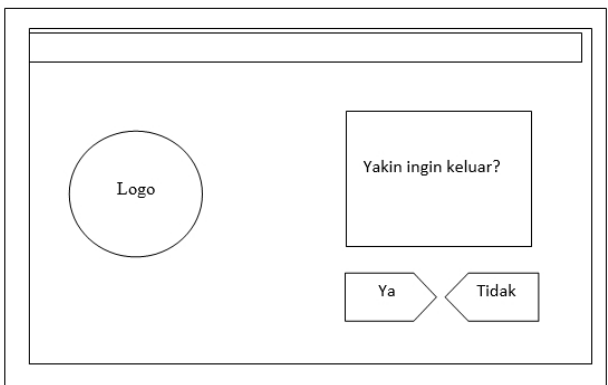

Gambar 13. Antarmuka Logout

Gambar 3.12 Menunjukkan untuk keluar dari Aplikasi Pembelajaran Interaktif Robotic Invention System platform Mindstorms NXT Berbasis Macromedia Flash Player Menggunakan Metode Inkuiri (Studi Kasus : Teknik Informatika Universitas Dhyana Pura).

\section{SIMPULAN}

Dari hasil penelitian yang dilakukan, maka penyusun menarik beberapa kesimpulan bahwa :

Penelitian ini mampu memberi solusi pembelajaran interaktif menggunakan aplikasi sebagai media untuk pembelajaran pembuatan robotika NXT yang praktis yang bisa di pelajari di-luar jam kuliah tanpa takut keterbatasan alat dan waktu.

Dengan adanya aplikasi Media Pembelajaran Interaktif ini diharapkan 
memudahkan mahasiswa dalam me-rakit robotika NXT diluar jam kuliah dan tanpa dosen pembimbing pada pembelajaran robotika lego NXT yang memuat tutorial berbentuk yang tidak hanya berbentuk video, juga di-sediakan dalam bentuk teks dan gam-bar.

\section{DAFTAR PUSTAKA}

[1] Adriyanto, Bambang. 2010. Pembuatan Animasi dengan Macromedia Flash. Jakarta: Kemendiknas.

[2] Asyhar, Rayandra. 2012. Kreatif Mengembangkan Media Pembelajaran. Jakarta: Ciputat.

[3] Irwanto, Andri. 2010. Implementasi Robot NXT Lego Pada Permainan Tic
Tac Toe, Tugas Akhir, Jurusan Tenik Informatika, Fakultas Teknologi Informasi, Institut Teknologi Sepuluh November, Surabaya

[4] Munir. 2009. Multimedia Konsep dan Aplikasi dalam Pendidikan. Bandung: CV

[6] Rahmawati, Yuli. 2015. Pengembangan Media Flash Berbasis Pembelajaran Inkuiri Untuk Meningkatkan Hasil Belajar Siswa. Tersedia di [http://journal.unnes.ac.id/nju/index.php JIPK/article/download/4828/3996] (diunduh : $24 \quad$ Mei 2016) 